\title{
EL DENOMINADO CONTRATO DE GARAJE Y EL APARCAMIENTO DE VEHICULOS
}

\author{
PURIFICACION CREMADES GARCIA
}

Colaboradora Honorífica Area Derecho Civil

\begin{abstract}
Al amparo del principio de libertad de contratación que inspira nuestro Derecho de obligaciones han surgido en la práctica contratos cuyas cláusulas obligacionales no resultan claras, es especial si se trata de contratos verbales, y que sin embargo se dan en el quehacer diario. Efectivamente, sólo cuando surge alguna duda referente a las obligaciones de una de las partes es cuando se plantea la verdadera naturaleza jurídica de dichos contratos. La doctrina tradicionalmente los ha venido denominando atípicos o mixtos, según que considerase que no tenían su reflejo en ninguna de las formas contractuales que aparecen tipificadas en el Código Civil, o bien si resultaban de la combinación de dos o más de estas figuras.
\end{abstract}

Riera Aisa (1) cita como figuras de contratos innominados -o atípicos que es el tecnicismo que va prevaleciendo para poder incluir así no sólo a los contratos que no tienen un nomen iuris sino además a los faltos de individualidad y reglamentación legal-, y que según él tienen cierto aspecto de generalidad y frecuencia, aparte de los que puedan nacer al calor de la voluntad y libre determinación de las partes, los siguientes: "los de hospedaje, pensión, exposición, deportivos, de asistencia o espectáculos públicos, garaje, educación, cinematográficos, de representación de obras teatrales, de publicidad, de circo o riesgo, de claque, de transporte en coche cama, de croceira o cruceros marítimos o terrestres o forfait, etc".

La doctrina científica registra entre alguno de dichos contratos, atípicos o mixtos, al denominado de garaje, entendiendo como tal a áquel por el que el propietario del automóvil concierta dejar su vehículo mediante remuneración en los locales que a este efecto le cede el garajista. La discusión surge en torno a si este contrato constituye un arrendamiento de cosas, un verdadero depósito, o bien un contrato atípico. Así lo delimita la Sentencia de la AP Madrid de 3 de Octubre de 1987: "El contrato de garaje es una convención atípica, surgida en el presente siglo como consecuencia de las necesidades de la vida moderna, que participa de los caracteres del contrato de arrendamiento de bienes inmuebles, del de servicios y del de depósito, pues el individual es únicamente un contrato de arrendamiento de cosa inmueble".

El sustrato último del problema que aquí se plantea radica en la misma naturaleza y régimen de los contratos mixtos, en el análisis de la norma jurídica que debe regularlos. Cabe señalar como teorias principales y contrapuestas en esta materia la tradicional o de la absorción que estima que se debe descubrir en los contratos mixtos la prestación o elemento principal que domine la totalidad del negocio y le imprima su carácter, y la de la combinación (iniciada por Hoeniger), según la cual deben combinarse las diversas prestaciones correspondientes a los diferentes contratos típicos que integran ese determinado contrato mixto. Sin embargo estudios 
recientes ponen de manifiesto que una y otra teoría son insuficientes para resolver los complejos casos que puede ofrecer la realidad. A juicio de Fubini (2) sólo la intención de las partes que ha constituído el contrato complejo puede dar un criterio positivo para resolver las dificultades y dudas que puedan surgir. Y será el examen de la convención originada el que decidirá de la posibilidad o no de afirmar si el fín perseguido por las partes puede ser alcanzado con un contrato nominado al cual se agreguen otras prestaciones impropiamente llamadas accesorías.

Roca Juan (3) mantiene que hay absorción cuando se pueda averiguar cual de las prestaciones constituyentes de su contenido es principal y cual accesorio, y combinación en cuanto se debe procurar la conciliación de la otras prestaciones con la que es absorbente y la aplicación de los principios generales en materia de obligaciones y procedimiento analógico y consideraciones de equidad como únicos medios de llenar lagunas legales que en cualquier caso, han de producirse si no hay una especial normativa consuetudinaría previamente reconocida.

Siguiendo a Enneccerus (4) podemos afirmar que "la solución compete siempre en última instancia al arbitrio judicial, atendiendo a las circunstancias del caso concreto, especialmente inspirandose en el fín económico y en los legítimos intereses de las partes".

Es por ello que no podemos encuadrar de forma taxativa al contrato de garaje dentro, o bien del contrato de arrendamiento, o bien dentro del contrato de depósito, y la única posibilidad que nos queda es determinar unas pautas previamente para saber si debe prevalecer uno u otro contrato, sin perjuicio de que la Autoridad Judicial considere que, atendiendo fundamentalmente al caso concreto, las consecuencias derivadas de unas determinadas notas en la relación jurídica pueden conrresponder bien a up tipo de contrato o a otro, o bien que el contrato de garaje participe de ambas figuras a la vez.

Según Roca Juan (5) se dice que puede calificarse de arrendamiento de cosas si el vehículo queda en un box, o aparcamiento cerrado, aun dentro de un local colectivo, y de depósito si el vehículo se queda abierto en un lugar colectivo sin reserva de plaza. Se aduce frente a la calificación como depósito, que el contrato que permite el uso continuado (retirar el vehículo y volverlo a dejar) es incompatible con el depósito, a no ser que se constituyan nuevos depósitos cada vez que el coche se deja, tal y como se dijo en la Sentencia de 10 de Junio de 1929. En contra se califica el contrato entre el dueño del vehículo y el propietario del garaje como depósito, partiendo de que el vehículo es cosa mueble que se instaló en el garaje para su custodia y por estimar notorio que el servicio principal de tales establecimientos es la guarda o custodia de vehículos de motor. Poniendo la principal atención en la posible responsabilidad del garajista por los deterioros que pueda sufrir el vehículo y que pueden ser evitados, Roca Juan considera que se ha llegado a una tercera tesis, la del contrato mixto, midiendose la responsabilidad por la genérica del artículo 1.094; contrato que origina una situación que para el garajista se compone de tres obligaciones: recibir el automóvil en el garaje, restituirlo y conservarlo (entrañando esta última la prohibición de utilizarlo), y sin que ello implique obligación de entre- 
tenimiento, salvo pacto especial. Por otra parte el local no es sustituible por otro distinto a áquel donde el vehículo se deja.

En este sentido "Son obligaciones del garajista las de poner un lugar suficiente, determinado o indeterminado, según las peculiares condiciones convenidas, a la disposición del usuario para la ubicación de su vehículo, la vigilancia del mismo y la obligación de devolverlo a su propietario en el mismo estado en que fue entregado, y el incumplimiento de daños y perjuicios en la forma que determinan los arts. $1.101,1.106 \mathrm{Cc}$; sus derechos se limitan a la recepción de la merced convenida y las generales derivadas de las normas de convivencia." (AP Madrid S. 3 Octubre 1987). De dicha Sentencia podemos deducir que los deberes de guarda y custodia o de vigilancia estan incluídos dentro de la diligencia que con carácter general se recoge en el artículo $1.094 \mathrm{Cc}$.

Sin embargo por lo general, tanto ia doctrina, y especialmente la jurisprudencia, han tendido más hacía la consideración del contrato de garaje como un contrato de arrendamiento, eximiendo de esta forma al garajista de la responsabilidad que puede derivarse por la guarda y custodia del vehículo. "No es inherente a los contratos de garaje la necesaria asunción por el dueño de una específica obligación de guarda y custodia; en efecto, es perfectamente imaginable, e incluso es frecuente en la realidad, un contrato de este tipo, en el que el dueño no se obliga más que a entregar la posesión de una parcela del local, con la correspondiente llave, a cambio de un precio cierto y durante un plazo determinado, de tal suerte que la figura contractual que en tal caso surge no es otra que la de un arrendamiento de cosa (art. $1543 \mathrm{Cc}$ ), con las obligaciones que para el arrendador determina el art. $1554 \mathrm{Cc}$., entre las que no figura las de custodia y sí la conservación del local en las condiciones adecuadas y mantener al arrendatario en la posesión pacífica de la cosa arrendada". (AP Bilbao S. 5 Marzo de 1987).

Sentencias más antiguas, como por ejemplo de 10 de Junio de 1929 llegaba incluso más lejos al afirmar que a pesar de tener el garajista el deber de guarda y custodia del automóvil en términos generales, por tratarse de un establecimiento público donde también se encierran otros coches y tienen facultad de entrar libremente sus encargados, esta obligación de vigilancia no desnaturaliza el arrendamiento para convertirlo en depósito de coches, pues a favor de la primera calificación lleva la finalidad del acto, la subsistenciádel contrato despues de sacar el coche para el servicio ordinario del dueño por tiempo indeterminado, y la parvedad y uniformidad de la retribución, tan desproporcionada con los riesgos y obligaciones de que habría de responder el dueño del local si fuese depositario, puesto que el precio es igual para los vehículos de todas las clases y tamaños.

Sin embargo las Sentencias más recientes afirman de forma taxativa la inexistencia de la obligación de guarda y custodia por parte del dueño del garaje. "Ni la buena fe, ni el uso o costumbre, ni la Ley imponen de modo necesario o señalan como de ordinario establecimiento que dentro del contenido obligacional de un contrato de garaje se asuma por el dueño del mismo una específica obligación de guarda y custodia, de tal suerte que ni la aplicación del artículo $1.258 \mathrm{Cc}$ conduce a afirmar como inherente al contrato aquella obligación, ni la aplicación del art. $1.287 \mathrm{Cc}$ 
lleva a afirmar por vía de interpretación, que en caso de ambigüedad tal obligación deba entenderse comprendida en el contenido contractual". (AP Bilbao S. 5 de Marzo de 1987).

"Será sólo la común voluntad de las partes al tiempo de contratar o, en su caso, la lógica deducción que los actos de una debían producir en la otra, la que determine la existencia de una obligación de guarda y custodia por el dueño del garaje y la extensión de ésta; siendo así que ninguno de los datos aportados a la litis muestra que efectivamente fuera voluntad común de los contratantes, como incluída en la oferta y como determinante de la aceptación, la asunción por el dueño del garaje de una obligación de guarda y custodia que se extendiera también a las horas distintas de aquéllas en que estaba prevista la existencia de un guarda, la presencia de éste a unas horas determinadas y la entrega a los usuarios de una llave que les permitiera la entrada y salida fuera de tales horas, en un estado de hecho que, en una deducción lógica, no debía pensar a quien decidiera contratar el uso de una parcela que el garaje se hallaría vigilado y custodiado todo el día, y sí sólo en aquellas horas". (AP Bilbao S. 5 Marzo 1987).

Un dato importante que hasta ahora parecen dar por supuesto las Sentencias mencionadas que eximen al garajista de la obligación de guarda y custodia es que la llave del local se entrega al propietario del vehículo, de esta manera dicho propietario podrá entrar y salir a su entera satisfacción, dificultando a su vez una posible misión por parte del garajista de guarda y custodia, debído a la afluencia de gente que puede poseer una llave y acudir a retirar o dejar su vehículo, entendiendo por tanto que nos encontramos ante un derecho de uso y goce de una cosa, de una parcela de terreno por el que se paga una cantidad ajustada precisamente a ese derecho de goce y disfrute, y que resulta insuficiente si además queremos con ello que se nos contrapreste con la guarda y custodia de nuestro vehículo.

En este sentido la Sentencia de 10 de Mayo de 1989 de la AP Madrid Sección 90: "Se trata de un contrato atípico. Entre las obligaciones del titular del aparcamiento no se halla la de responder de la sustracción, dado lo exiguo del precio satisfecho y el hecho de entregarle a los distintos propietarios de los vehículos una llave del local sin que nadie garantizase la vigilancia y cuidado, existiendo además un cartel que eximiera a la empresa por robo".

Sin embargo, en los últimos años ha surgido una nueva modalidad en el aparcamiento de vehículos, que consiste en dejar el mismo en un lugar cerrado o vallado, sin reserva previa de plaza, y que se paga en virtud de las horas que efectivamente el coche ha permanecido en el mencionado lugar, son los conocidos con el anglicismo de parkings, y se diferencian del antiguo contrato de garaje antes estudiado, entre otros rasgos porque el propietario del vehículo no se queda con la llave del local, sino que éste permanecerá abierto las veinticuatro horas o bien tendrá un horario determinado, pudiendo retirar su vehículo el dueño del coche previo pago de una cantidad que dependerá del número de horas que el vehículo haya permanecido estacionado en el local. Así a la diferencia antes enunciada podemos añadir una segunda y es que no se paga en virtud del espacio ocupado sino del tiempo. Otro 
dato importante a tener en cuenta es que generalmente el vehículo se estaciona cerrado dentro del local.

Así estas tres notas, a saber, no entrega de la llave del local al propietario del vehículo, pago de una contraprestación en función del tiempo que el coche permanece en el local, y no entrega al dueño del local de la llave del vehículo, parece acercarnos más a un verdadero contrato de depósito que a un contrato de arrendamiento, hay intención por parte del propietario del vehículo de entregar éste para su guarda, custodia y posterior devolución. Según el artículo 1,769, cuando la cosa depositada se entrega cerrada y sellada, debe restituirla el depositario de la misma forma y responde de los daños y perjuicios si se cortara el sello o cerradura por su culpa. No cabe duda de que el vehículo se entrega cerrado, y de que de la perpetración de un robo con rompimiento de un cristal del vehículo, puede derivarse una culpa imputable al depositario o garajista si se demuestra que había ausencia total de medios o personas que garantizasen la custodia del vehículo estacionado, existiendo así una presunción iuris tantum contra el depositario en el sentido de tener que demostrar que efectivamente existian los mencionados medios. Dicho precepto esta en íntima conexión con el artículo 1,767 que establece que el depositario no puede servirse de la cosa depositada sin permiso expreso del depositante, o en caso contrario responderá de los daños y perjuicios, obviamente si no se puede utilizar el vehículo objeto del depósito, es por ello que las llaves del mismo no se dejan al garajista.

En cuanto a la falta de entrega de las llaves del local por parte del garajista al propietario del vehículo, resulta el signo más evidente de que no estamos ante un contrato de arrendamiento, ya que no se produce una trasmisión de la posesión del local (o parcela asignada para el estacionamiento), pues según el artículo 1.467 y aunque se trate de una disposición aplicable a los bienes muebles, es costumbre hacerlo en el arrendamiento de inmuebles por cuanto la entrega de llaves posibilita franquear la puerta del local.

En lo referente a la relación que existe entre tiempo o duración, viene a corroborar la existencia de un contrato de depósito, ya que independientemente del tamaño del turismo y por lo tanto del espacio que ocupe, se fija una cantidad que depende del tiempo de permanencia.

Así por lo tanto, si alguna duda podía reportarnos la calificación del garaje entendido en sentido tradicional, es decir, la entrega y permanencia de un vehículo en un local destinado a tal efecto y donde se encuentran otros vehículos de diferentes propietarios, que generalmente poseen una llave del local, quedando en ocasiones su propio vehículo abierto dentro del mismo; sin embargo del devenir de los tiempos ha creado una nueva figura o modalidad, donde el propietario generalmente deja unas horas estacionado su vehículo en el local del garajista, éste permanecerá cerrado y como nota fundamental, el local estará abierto al público, con lo que el propietario del coche no necesitará llave para acceder a recogerlo. Antes, y debido fundamentalmente a la tenencia de la llave del local por parte de cada propietario, hacía que dicha figura se acercase más a un arrendamiento de cosas que a un depósito, y así lo ha considerado la jurisprudencia, eximiendo por lo tanto al garajista de 
la guarda y custodia, y utilizando para ello como hemos visto, diferentes argumentos. Ahora bien, con la nueva figura creada, no cabe duda que nos encontramos en principio ante un contrato de depósito, y que como tal, la obligación fundamental del garajista es la guarda y custodia. Cabe entonces preguntarnos el límite de esta obligación. Analizaremos para ello cuatro temas fundamentales:

En primer lugar el hecho de que la constancia de la entrega suele consignarse en un ticket, al igual que se hace en los guardarropas de los teatros o restaurantes o en las consignas de estaciones o aeropuertos, en estos supuestos en los tickes suele plasmarse un número que ni siquiera existe en algunos tickes de garaje. Así éstos se convierten en la única prueba de la existencia del depósito, prueba que no contiene firma alguna, ni descripción del objeto depositado, ni lugar exacto en que se realiza el estacionamiento, y hasta incluso en ocasions la fecha y hora de entrada del vehículo. El ticket se convierte así en una especie de título al portador, fundada en una presunción de que el poseedor del ticket es aquél que estacionó el coche, pero que en realidad puede o no ser la persona que lo realizó, éste podrá retirar el vehículo a la entrega del resguardo, sin responsabilidad alguna en este sentido por parte del garajista que no tendrá que exigir justificación de la tenencia de dicho resguardo, por lo que no responderá en caso de pérdida del vehículo si logra demostrar que el coche lo entregó previa presentación a su vez del resguardo. Este tampoco contiene la identidad o modelo del vehículo, ni el estado en que se encuentra o el valor de los objetos que pueda contener, con lo que la carga de la prueba en caso de deterioro o robo de los objetos depositados en el interior correrá a cargo del propietario del vehículo (artículo 1.214 C.c.). Ahora bien, la prueba se limitará al estado previo en que se encontraba el vehículo antes de la entrada en el garaje, si resulta evidente que éste se produjo en el interior, por existir señales fidedignas que lo demuestren, por ejemplo restos de cristales en el suelo localizados al lado de donde tiene el vehículo el daño y de los que se deduce que el coche aparcado en ese mismo lado pudo haber colisionado con el primero, entonces la carga de la prueba se invierta y deberá ser el garajista quien demuestre que actuó con la debida diligencia en la guarda y custodia del vehículo. Estaremos en presencia de una situación similar para el caso de robo con fractura de una de las ventanillas del coche por ejemplo; resulta también evidente que los restos de dicha fractura en el suelo y el desorden en el interior del vehículo pueden demostrar por si solos que el robo se produjo en el interior del local, en este caso el garajista tambien responderá de los daños producidos en ausencia de diligencia para la guarda y custodia, sin embargo no podrá responder del valor de los objetos robados ya que previamente no ha habido una identificación de los mismos por parte del propietario del vehículo. Una sentencia reciente de 2 de Abril de 1991 del Juzgado de Primera Instancia $\mathrm{n}^{\mathrm{0}} 31$ de los de Barcelona considera que "la obligación de custodia que prevee el artículo 1769 del Código Civil presume en el párrafo segundo la culpa del depositario y negligencia de la custodia cuando no se devuelve la cosa depositada, y así se desprende de lo actuado, la prueba en contrario no ha sido ni siquiera intentada, la obligación de responder ha de ser una consecuencia necesaria.", por lo que condena a la Empresa garajista a reintregrar no sólo los daños por la rotura de los cristales del vehículo, de lo que en el presente 
caso se hizo cargo de forma voluntaria la mencionada empresa, reconociendo así parte de su responsabilidad como se dice en dicha Sentencia, sino incluso condenando a la misma a pagar al propietario del vehículo el importe del radio-casette que le fue sustraído, ante la ausencia de pruebas que eximiesen a la Empresa de la responsabilidad por su calidad de depositaria. Desconocemos en el presente caso la prueba practicada por el demandante, si bien suponemos que existió por lo menos una mínima actividad probatoria en relación con un modelo determinado de radio-casette, y así calcular su valor concreto, supliendo así la identificación previa a la que aludíamos antes.

Otro problema que se puede plantear es el caso de que se produzca un hurto del vehículo, encontrándose el propietario en la posesión de un resguardo que nada dice de las características del coche que allí depositó, es decir, que al intentar sacar su vehículo del garaje contra entrega del resguardo que le fue facilitado al estacionarlo, el mismo no se encuentra en el local donde lo estacionó. ¿Existiría una presunción de que efectivamente el propietario dejó el vehículo que manifiesta?, pienso que realmente se trata de un problema de difícil solución ya que como hemos dicho en el en el ticket no se plasma el modelo o las características del coche que se estaciona, por lo que resutaría totalmente injusto presumir que la manifestación del usuario del vehículo es la válida, así sería éste último quien tendría que probar que efectivamente el ticket corresponde a la entrada de un determinado vehículo, lo que por otro lado no resulta nada sencillo.

En segundo lugar no debemos olvidar un aspecto de este tipo de contratos que afecta de manera fundamental a su efectividad jurídica. Se trata de contratos verbales, dificilmente podemos considerarlos escritos, ya que a pesar de que en ocasiones las condiciones se plasman en el ticket, éste no podemos valorarlo ni siquiera como un esbozo de contrato, el ticket como tal no deja de ser un mero resguardo acreditativo de un hecho. Otras veces las condiciones se encuentran escritas en grandes rótulos en lugar visible para los usuarios de los vehículos. En cualquier caso las mismas estan impuestas por el garajista y aceptadas tácitamente por el propietario del vehículo, lo que nos aproxima a la existencia de un contrato de adhesión. Resulta evidente que en la confección o redacción de las condiciones contractuales no interviene el propietario del vehículo, fundamentalmente por una razón lógica, la celeridad del tráfico, permitiendo así al garajista formalizar muntitud de contratos en un sólo día. Sin embargo la formalización de este tipo de contratos no llega ni siquiera a poder considerarse como un contrato de adhesión, ya que la vaguedad de sus condiciones resulta aun mayor (6).

Diez Picazo y Gullón (7) consideran dentro de lo que la doctrina alemana llama "Prestaciones de tráfico en masa" la utilización de un aparcamiento de vehículos; éstas se encuadran como una categoría de las "relaciones contractuales de hecho" (4) dicho concepto no es sino un intento de explicar unas relaciones jurídicas similares a las contractuales pero donde falta la necesaria declaración de voluntad; así entre lo que ellos denominan "prestaciones de tráfico en masa" pensemos como ejemplos más evidentes en la utilización por parte de los ciudadanos de un servicio público, con la consecuencia necesaria de tener que pagar una tasa o la propia utili- 
zación de máquinas automáticas. Estamos en presencia de unas relaciones jurídicas en todo iguales -siguiendo a los mencionados autores- a lo que ocurre cuando una persona estaciona su vehículo en un parking, es decir realiza un determinado comportamiento del que nace una obligación, en este caso pagar un precio. Larenz ha hablado en estos casos de una conducta social típica como fuente de obligaciones distinta del negocio jurídico. Diez Picazo y Gullón consideran que querer reducir estas hipótesis a figuras contractuales no pasa de ser una ficción, y que no hay por consiguiente en ellas verdadera relación contractual, pero sí relaciones obligatorias derivadas de una conducta social.

Sin embargo, adimitir dicha postura no soluciona el problema ya que habría entonces que buscar cual es el régimen de dichas prestaciones para llenar esta laguna legal. La única solución posible sería acudir a los principios generales en materia de obligaciones y principios de equidad, y en último término a un procedimineto analógico, lo que nos conduciría inexcusablemente a una figura o figuras cotractuales típicas.

En tercer lugar, la mayoría de los tickes o fustificantes, además de excluir la responsabilidad de la empresa de parking por robo, hurto o daños causados por terceros, incluso en ocasiones llega a afirmar que no se trata de un contrato de depósito el estacionamiento del vehículo, ni de los objetos de su interior. Como ya hemos dicho anteriormente, los objetos que se encuentran en el interior del vehículo no pueden constituirse en depósito ya que en primer lugar éste no es la causa del contrato y en segundo lugar porque falta una identificación previa de los mismos y sus características. Sin embargo en lo referente a la negación de la calificación de este contrato como de depósito, hay que llevar entorno a este extremo un criterio interpretativo siguiendo los principios generales de las obligaciones y los contratos en nuestro Código Civil, debiendo ser los propios Jueces quienes deban ostentar facultades interpretativas y basándose siempre en principios de equidad, teniendo así un poder excepcional, similar al que podría tener en un contrato de adhesión, que les autorice a no aplicar las cláusulas del contrato más que en consideración a la situación particular de las partes, e incluso un poder de revisión que les autorizaría a modificar el contrato en la parte que apareciera como injusta. Podríamos acudir al artículo 1288 y en este caso tendría que sufrir las consecuencias la Empresa de Parking que es la que ha dado lugar a la imprecisión o vaguedad; sin embargo en mi opinión se podría llegar más lejos ya que para interpretar los términos de un contrato según nuestro Código Civil, siguiendo una dirección espiritualista, hay que estar a la intención de los contratantes, con independencia de los términos utilizados; si consideramos que se trata de un contrato en el que existe una parte en la relación cuya voluntad no se exterioriza, habrá que llevar a cabo un proceso lógico para dilucidar cual fue esa voluntad en el momento en que su comportamiento inicial se produjo. Por tanto es fundamental analizar la intención del propietario del vehículo, y ésta sin lugar a dudas es tendente hacia un tratamiento especial hacia su vehículo, una guarda que de no recibirla le sería indiferente estacionarlo en el parking o en la vía pública (8).

En cuarto lugar las responsabilidad del garajista podemos ponerla en relación 
con la del fondista o mesonero. El Código Civil considera también depósito el de los efectos introducidos por los viajeros en las fondas o mesones, sin embargo es requisito imprescindible que previamente el viajero ponga en conocimiento del fondista los objetos depositados (artículo 1783), consideración esta última ya comentada al hablar de los objetos depositados en el interior del vehículo, y es que difícilmente se puede responder de algo que previamente no ha sido identificado, de ahí que como también hemos dicho sería conveniente idear alguna fórmula con la que identificar la marca, matrícula y características generales del vehículo que se estaciona, salvando así un elemento de prueba difícil de superar para ambas partes. En el artículo 1784 se delimita la responsabilidad de los fondistas que no es solamente extensiva a los actos dañosos de los dependientes como lo sería por simple aplicación al Derecho Común, sino también a los actos de los extraños, pero no los que provengan de robo a mano armada o sean ocasionados por otro suceso de fuerza mayor. El precepto parece asimilar la fuerza mayor al robo a mano armada, para excluir este último de forma expresa, sin embargo extiende la responsabilidad no sólo a los daños causados por los dependientes, sino también a los acusados por "extraños"; así por lo tanto a pesar de las diferencias en cuanto a las circunstancias en las que nace el contrato, es decir, que el depósito de los efectos en el contrato de hospedaje se constituiría como accesorio, sin embargo podríamos encontrar un punto de conexión, y es que la responsabilidad se extiende a actos de extraños, lo que por otro lado se entiende con dificultad si excluímos el robo, en especial si se logra probar que había una ausencia total de medios que asegurasen la guarda de los objetos (medidas de seguridad).

Así las necesidades de los tiempos actuales en las ciudades, en especial el aumento del tráfico rodado y la propia inseguridad ciudadana, han hecho que se produzca el surgimiento, paralelo a lo que ya podríamos denominar tradicionales contratos de garaje, otros de aparcamiento de vehículos, cuyas notas relevantes se acercan más a un contrato de depósito que a un arrendamiento, pero que sin embargo necesita de un proceso interpretativo atendiendo fundamentalmente a la ambigüedad casuística que los diferentes supuestos de hecho pueden llegar a producir.

Efectivamente, debido a la ausencia de regulación legal, el Juez necesita en la resolución del caso concreto de un proceso interpretativo atendiendo fundamentalmente a las circunstancias en las que nació la relación, es decir sin la prevía exteriorización de la voluntad por el propietario del vehículo, pero sin que ello impida que por medio de un procedimiento analógico, y previa deducción lógica llegar a la voluntad que subyace en el momento de la entrada en el parking.

Ahora bien aunque sus notas se acerquen más a un contrato de depósito y probablemente dicha interpretación siempre resulte más beneficiosa para el usuario o propietario del vehículo, no podemos ser radicales en dicha afirmación ya que como se ha dicho antes es fundamental el proceso interpretativo del Juez a la vista de la situación concreta y pruebas, y además y aunque sólo sea ésta una situación imaginable como ficción, como problema de laboratorio, pensemos en la posibilidad que tendría el garajista o propietario de empresa de parking, si considerando formalizado un contrato de depósito sin más, retiene en prenda el vehículo hasta el pago com- 
pleto de la cantidad, siempre irrisoria en relación con el valor no sólo del vehículo, sino del perjuicio que puede causar dicha inmovilidad a su usuario, apoyándose en el tan claro precepto del artículo 1780 de nuestro Código Civil.

Por todo ello no se puede sino concluir diciendo que la regulación legal de la figura como tal resolvería situaciones y desequilibrios actualmente inevitables y es que, la Ley debe ir a la par con la realidad en constante evolución.

\section{NOTAS:} 489.

(1).- Nota en CASTAN: Derecho Civil Común y Foral. Tomo III. Madrid 1983, pág.

(2).- FUBINI: Contribución al estudio de los contratos complejos en Revista de Derecho Privado, 1931, págs. 1 y ss.

(3).- ROCA JUAN: El contrato de exposición, Murcia, Publicación del Seminario de Derecho Privado, 1984, pág. 28.

(4).- ENNECCERUS: Tratado, T. II, vol. $2^{o}$, pág. 7 de la $3^{a}$ edición española.

(5).- ROCA JUAN: Comentarios al Código Civil y Compilaciones forales dirigidas por Manuel Albaladejo. Tomo XII, vol. I, pág. 199, Madrid 1986.

(6).- En efecto los contratos de adhesión se caracterizan en palabras de Messino, por la imposición de determinadas claúsulas o del completo esquema del contrato por parte del contrayente económicamente más fuerte, en sentido ventajoso para él y en detrimento del otro contrayente, el cual siendo económicamente más débil, no tiene libertad de escoger, sino entre aceptar aquellas claúsulas o aquel esquema, o renunciar a la celebración del contrato $(*)$ (Nota 2 en la obra de Castán: Derecho Civil Español Común y Foral. Tomo III. Madrid 1983. Pág. 472). Sin embargo en el tipo de contratos que nos ocupa, ni las condiciones se plasman minuciosamente, y aun más, ni siquiera en el ticket, ni en cualquier otro documento se plasma la firma del propietario del vehículo en prueba de conformidad.

(7).- Cf. DIEZ PICAZO Y GULLON: Sistema de Derecho Civil. Tecnos Madrid 1983. Pág. 37-38.

(8).- Tendríamos por tanto que seguir un criterio similar al utilizado por la Ley General par la Defensa de los Consumidores y Usuarios 26/1984, de 19 de Julio que establece en su artículo décimo, punto segundo que "A los efectos de esta Ley, se entiende por claúsulas, condiciones o estipulaciones de caracter general, el conjunto de las redactadas previa y unilateralmente por una Empresa o grupo de Empresas para aplicarlas a todos los contratos que aquéllas o éste celebren, y cuya aplicación no puede evitar el consumidor o usuario, siempre que quiera obtener el bien o servicio de que se trate."; según la referida Ley dichas cláusulas, condiciones o estipulaciones deben cumplir la buena fe y justo equilibrio de las contraprestaciones, lo que entre otras cosas, excluye: Las limitaciones absolutas de responsabilidad frente al consumidor o usuario. (art. décimo, apartado primero, subapartado c-6o). Así según el articulado de esta ley, serían nulas las condiciones que limitasen dicha responsabilidad (apartado cuarto). 